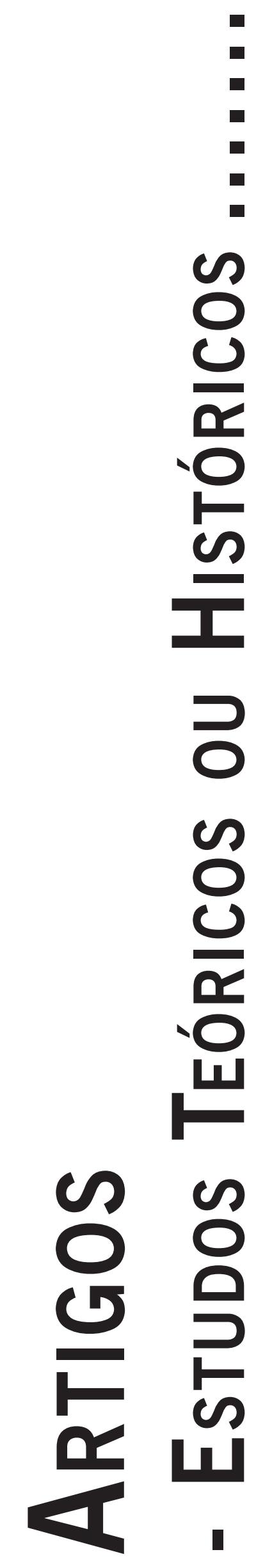




\title{
ARTICULAÇÃO ENTRE HERMENÊUTICA E FENOMENOLOGIA PARA UMA CLÍNICA PSICOLÓGICA COM BASES HEIDEGGERIANAS
}

\author{
An Articulation between Hermeneutics and Phenomenology for a Heideggerian-based Psychological Clinic
}

Articulación entre Hermenêutica y Fenomenologia para una Clínica Psicológica com Bases Heideggerianas

Jean LuCa Lunardi Laureano da Silva

Marina Valente Guimarẽes Cecchini

\begin{abstract}
Resumo: A aproximação de uma clínica fenomenológica hermenêutica com vistas à ontologia fundamental de Heidegger se dá através da articulação entre as propostas de Dilthey e Husserl. O surgimento destes últimos dois filósofos no século XIX culminou com movimentos chamados antipositivistas. O movimento destas duas viradas filosóficas teve início para que fosse buscado o rigor que a filosofia perdeu através de sua subordinação aos métodos científicos postulados pelas concepções das ciências naturais. A proposta da hermenêutica surge para se articular o fenômeno em seu horizonte historicamente constituído através de uma semântica histórica, a fim de que este seja compreendido a partir do seu nexo vital e total. Já a fenomenologia surge com o método intencional, juntamente com a suspensão (epoché) e a redução fenomenológica a fim de que as coisas como elas mesmas possam se dar sem imersão em teorias. A proposta deste estudo é uma revisão de literatura para embasar a importância da hermenêutica como historicismo e a fenomenologia como método intencional para proposta da ontologia fundamental heideggeriana e aproximar de uma atuação clínica em psicologia, a Daseinsanalyse.
\end{abstract}

Palavras-chave: Dilthey; Husserl; Heidegger; Psicoterapia.

\begin{abstract}
The approximation of a phenomenological hermeneutical clinic regarding Heidegger's fundamental ontology is achieved through the articulation between the proposals of Dilthey and Husserl. The emergence of these two philosophers in the nineteenth century culminates in antipositivist movements. The movement of these two philosophical approaches began so that it could be possible to seek the rigor which had been lost due to Philosophy's subordination to Natural Sciences' methods. The hermeneutical proposal arises to grasp the phenomenon in its historical horizon, through historical semantics, in order to understand it from its vital and complete nexus. Phenomenology, on the other hand, comes up with the intentional method, along with suspension (epoché) and phenomenological reduction so that things as themselves can occurr without immersions in theories. This paper aims at reviewing the literature to support the importance of hermeneutics as historicism and phenomenology as an intentional method to Heidegger's fundamental onthological proposal, approaching a clinical performance in psychology, the Daseinsanalyse.

Keywords: Dilthey; Husserl; Heidegger; Psychotherapy.

Resumen: El acercamiento de una clínica de fenomenológica hermenêutica con la perspectiva de la ontología fundamental de Heidegger ocurre a través de la relación entre la propuesta de Dilthey y Husserl. El surgimiento de estos dos últimos filósofos en el siglo XIX culminaré con los movimientos llamados anti-positivista. El movimiento de estos dós pensamentos filosóficos tuve inicio para que fuese buscada el rigor que la filosofía habia perdido a través de su subordinación a los métodos científicos postulados pelos conceptos de las ciencias. La propuesta hermenéutica surge para articular el fenómeno en su horizonte historicamente constituido por una semántica histórica, a fin de que este sea compreendido a partir de su nexo vital y total. Todavia la fenomenologia surge com el método intencional, juntamiente con la suspensión (epoché) y la reducción fenomenológica a fin de que las cosas como ellas mismo puedan darse sin inmersión em teorias. La propuesta de este estudio es una revisión de la literatura para apoyar la importancia de la hermenéutica como historicismo y la fenomenología como método para la propuesta ontología fundamental heideggeriana y acercarse de una atuación clínica en la psicologia, a la Daseinsanalyse.

Palabras clave: Dilthey; Husserl; Heidegger; Psicoterapia.
\end{abstract}

\section{Introdução}

O presente artigo se ocupa na busca de fundamentação para uma clínica psicológica que escape dos moldes atuais. Estes se encontram imersos em teorias e concepções positivo-naturais que apenas limitam e obscurecem as vivências do paciente que procura auxílio na clínica, no sentido de que buscam respostas e fundamentações prontas, compreendendo muitas vezes aquele que busca ajuda como detentor de um psiquismo ou como um mecanismo determinado pelo meio. Estas ideias simplesmente ignoram a própria vivência particular, que é muito mais do que uma teoria pode compreender, e que iremos esclarecer com detalhes no presente trabalho. A tarefa de se pensar uma clínica que consiga superar as insuficiências de nosso tempo, nos remete diretamente ao tratamento 
do que iremos chamar aqui de clínica fenomenológica hermenêutica (Ferreira, 2009, 2010; Sá \& Santos, 2011). Esta clínica está inserida em um movimento filosófico muito particular, e nossa ocupação consiste em desvelar este mesmo horizonte de consideração, e, a partir disso, aproximá-lo das considerações psicológicas.

Mas em que medida se pode realizar tal busca? Como escapar das considerações positivistas de nosso tempo? Estas questões podem ser respondidas com o retorno às considerações realizadas por Edmund Husserl (1859-1938) e Wilhelm Dilthey (1833-1911). Mas antes mesmo de se pensar suas contribuições, se faz necessário percorrer pela conjuntura histórica em que estes dois pensadores se inseriram. Desta maneira, é preciso compreender a chamada crise dos universais ${ }^{1}$, e só depois apontar a forma como tanto Husserl como Dilthey inserem suas propostas no âmbito filosófico. Com este percurso já realizado podemos nos aproximar do pensamento de Martin Heidegger (1889-1976), e de sua ontologia fundamental, presente em Ser e Tempo (Sein und Zeit), 1927.

O último caminho a ser trilhado passa a ser a possibilidade de se pensar essa articulação realizada por Heidegger, entre o pensamento de Husserl e Dilthey, para uma clínica psicológica que busque as vivências particulares de cada um. Afirmar isso implica em não buscar explicações prévias acerca daquilo que se apresenta para o paciente na clínica, mas deixar que o fenômeno apareça por ele mesmo, e que ele possa ser compreendido histórica e faticamente.

\section{A crise dos universais}

Em Dilthey (1894/2011) são assinaladas as insuficiências geradas tanto pelo realismo quanto pelo idealismo (as duas correntes filosóficas mais influentes do século XIX) que acabam por deixar o homem europeu em intensas considerações relativistas e céticas acerca dos fenômenos em geral. De um lado, o realismo aponta para as verdades que estão no mundo sem o alcance direto de uma subjetividade encapsulada, ou seja, para se chegar a tais verdades, segundo Lessa (2011), é preciso se despir das particularidades que caracterizam um indivíduo e obter o próprio fenômeno em um plano "real". Acontece que toda esta busca por um espaço eterno e imutável, de verdades últimas e absolutas fica impossibilitada de ser alcançada devido às influências que o próprio sujeito cognoscente carrega em si mesmo, ou seja, mesmo se despojando de seus elementos particulares não se consegue, às últimas consequências, alcançar essas possíveis verdades que estão contidas na "realidade".

Já o idealismo é concebido como a corrente filosófica que, segundo Lessa (2011), passa a não buscar os fenô-

A crise do universal também é citada na literatura em geral como crise dos fundamentos, crise da filosofia ou também crise da razão. menos em espaços reais, mas sim centrados na própria subjetividade do sujeito. O idealismo, radicalizado principalmente em Kant (1724-1804), vai se voltar à subjetividade como a única possibilidade de conhecimento da verdade. O problema do idealismo passa a ser a própria maneira em que este se constitui, ou seja, a verdade pode ser uma forma de "ilusão", por estar centrada simplesmente em um aparato subjetivo. O que se afirma com isso é a impossibilidade de conceber a própria questão da verdade a partir de determinações subjetivas.

Desse modo, a modernidade europeia se encontrava em um momento de crise, onde o conhecimento passou a ser relativizado. A partir da insuficiência que a própria filosofia estava passando, na tentativa de se explicar os fenômenos na totalidade, ela acabou, necessariamente, se aproximando dos ideais científicos. O modo como esta aproximação se dá, será fundamental para a forma como a filosofia irá ser levada a cabo, e proporcionará que tanto Husserl quanto Dilthey se insiram numa mudança de todas estas concepções.

Cabe agora pensar como o movimento positivista se constitui, pois só assim conseguimos penetrar profundamente nas considerações mais importantes da crise que estamos procurando compreender. O idealizador do movimento positivista, o filósofo Augusto Comte (17981857), buscou para a sua nova ciência, a sociologia, meios de fundamentação a partir dos ideais científicos da época. Porém, a própria maneira em que Comte irá inserir a sociologia, será tão influente que a ciência em geral irá se apropriar do modo de pensar radicalizado pelo positivismo. De acordo com Lacerda (2009), o positivismo de Comte pode ser caracterizado principalmente por três aspectos fundamentais. A primeira consiste em uma negação da teologia e da metafísica. A segunda, diz da necessidade de se tratar os objetos de estudo da ciência, a partir da empiria, da experiência dos "fatos puros". E, por último, a colocação da ciência como o "conhecimento verdadeiro da realidade".

O caminho já estava preparado para que a filosofia buscasse a fundamentação de seus próprios métodos, devido às insuficiências que esta apresentava em seu cerne. E é no próprio movimento positivista que essa fundamentação aconteceu. A partir disso, a filosofia se encontrava cada vez mais subordinada aos métodos e concepções positivistas, e perdia seu próprio lugar, como possibilidade de conhecimento rigoroso. É desta maneira que, de acordo com Feijoo (2011a), a filosofia, desde as formulações de Descartes, passa a tratar daquilo que podemos designar de dicotomia sujeito e objeto. Esta dicotomia consiste na separação de um sujeito cognoscente e de um mundo de objetos passíveis de serem apreendidos por uma subjetividade segura de si.

Porém, esses mesmos ideais positivistas que o homem europeu acreditou serem as únicas formas de se considerar todo e qualquer fenômeno, acabaram, segundo Goto (2007), desmoronando em seus propósitos iniciais. Isto é 
afirmado quando a filosofia e a ciência em geral passam a desconsiderar o caráter humano e a existência em si de suas formulações. A partir disso, todo o movimento positivista das ciências em geral, principalmente nas ciências naturais, como a física e a biologia, acaba fazendo com que a razão perdesse a força e a hegemonia que tinha conquistado. Até mesmo as formulações de Descartes, como a da scientia, ou seja, da própria ciência rigorosa e segura, passam a cair por terra.

Com tudo isso, podemos perceber de que maneira esta crise pode ser colocada como a "crise dos universais". O que está em jogo aqui é a forma como toda a ideia de universalidade cai por terra, por não se conseguir mais, consistentemente, sustentar fundamentos últimos e seguros acerca dos fenômenos em geral. Dessa forma, tanto a filosofia quanto a ciência não podem mais responder e se propor a buscar qualquer conhecimento acerca da verdade.

\section{A fenomenologia intencional de Husserl}

A proposta fenomenológica de Husserl só é possível de ser pensada pela descrição da conjuntura em que ela mesma vem a ser inserida. Este horizonte mesmo é o que acaba de ser colocado como marcado consistentemente pela "crise dos universais". Portanto, estas passam a ser a herança filosófica de Husserl e, mais do que isso, passam também a ser a própria possibilidade da fenomenologia se constituir como uma nova possibilidade em relação a todas estas teses científicas e filosóficas que estavam imersas nas considerações positivistas. Porém, mais do que simplesmente servir de superação, o próprio pensamento de Husserl acaba se apropriando de muitas influências que marcam o próprio movimento da crise. Cabe ressaltar algumas destas influências para podermos compreender de que maneira podemos pensar a fenomenologia. De acordo com Depraz (2011), Husserl se aproxima de Descartes e de seu método da dúvida metódica, e se apropria deste rigor cartesiano para pensar a sua epoché, que iremos descrever posteriormente. Descartes formula sua dúvida metódica, como busca de um método filosófico rigoroso, de duvidar sistematicamente dos objetos que se apresentam para um ego, um "eu" que não é questionado, pois serve como verdade absoluta. Contudo, Husserl formula a sua epoché como a suspensão dos pressupostos e crenças. Mais do que duvidar, Husserl coloca todos os posicionamentos acerca das coisas em um momento negativo, que não os exclui, apenas os suspende momentaneamente. A própria questão do ego em Husserl é questionada, diferentemente do pensamento de Descartes.

Já de Kant, Husserl se apropria da questão de uma subjetividade dinâmica, ou seja, não aquela interiorizada e separada pelo cartesianismo. Segundo Lessa (2011), o sujeito kantiano é aquele que ao mesmo tempo em que dá certa importância para os fatos empíricos, é somente através da subjetividade e de suas estruturas a priori que se pode buscar o aspecto da verdade em si mesma. Entretanto, Husserl não trabalha com estas mesmas estruturas a priori, mas questiona o modo com que os simples fatos empíricos podem trazer qualquer possibilidade de verdade, por eles mesmos. Isso nos remete diretamente à crítica realizada ao realismo, que considerava a verdade independentemente do sujeito cognoscente. Esta possibilidade de se considerar o sujeito, a subjetividade em si, é marcante também na fenomenologia hegeliana. Diferente da proposta da fenomenologia de Husserl, Hegel (17701831) entende que nada além da subjetividade pode vir a ter algum caráter que se aproxima da verdade. Porém, Husserl não se limita ao aspecto subjetivo ao considerar que os fenômenos em si mesmos contêm a necessidade de serem estabelecidos de maneira também empírica. Em relação a este caráter empírico, Depraz (2011) aponta como o caráter ideal em Husserl só pode ser estabelecido a partir da relação com os fatos empíricos. Desta forma, não pode se descartar como a experiência possibilita, através da epoché, alcançar o caráter ideal dos fenômenos em geral.

A última influência direta de Husserl, antes da formulação de sua fenomenologia, passa a ser a de seu mestre Franz Brentano (1838-1917). Este é conhecido devido às suas importantes formulações filosóficas e psicológicas. E é este último caráter, o da psicologia, que fará com que Husserl comece a buscar na mesma, a possibilidade de propor um novo olhar e método para as crises que marcavam o homem europeu. Brentano, em um resgate do pensamento escolástico, encontra o conceito de intencionalidade, e que irá descrever fundamentalmente o seu projeto: o de uma psicologia descritiva, que será de importância fundamental para as considerações ulteriores. De acordo com Boris (2011), ao tratar da importância de Brentano, afirma que seus "ensinamentos, especialmente sua Psicologia descritiva, influenciaram o movimento fenomenológico no século XX" (p. 194). A psicologia descritiva, ao se apropriar da intencionalidade passa a excluir o tratamento dos fenômenos a partir do olhar da dicotomia sujeito e objeto. E esta intencionalidade aponta diretamente para o caráter psíquico, e seus próprios atos e objetos correlatos, como: pensar-pensado, imaginar-imaginado. Husserl pensa a intencionalidade a partir desta proposta de superar a intensa dicotomia que existia, desde o próprio surgimento da filosofia e, principalmente, com o cartesianismo. Seguindo a influência de seu mestre Brentano, há a procura na psicologia, de um método diferente dos científico-positivistas. Porém, esta psicologia que surgia há pouco tempo, com os laboratórios experimentais de Wilhelm Wundt (1832-1920), também não estava salva das influências do positivismo, e a forma com que Husserl irá levar a cabo esta psicologia será imensamente criticada. Esta forma de psicologia é o próprio psicologismo, que afirmava que todo e qualquer fenômeno estava subordinado às leis que regem o psiquismo. Após ser muito criticado no meio acadêmico, Husserl começa a se aproximar de uma nova forma 
de se pensar a psicologia. Segundo Holanda (2009), a fenomenologia passa a precisar da forma como a psicologia pensa os fenômenos psíquicos, e, ao mesmo tempo, a psicologia também necessita do próprio método fenomenológico para não se inserir nas mesmas determinações que as ciências naturais. Isto é afirmado no sentido de que a psicologia, nascendo em um âmbito positivista acaba precisando de uma fundamentação rigorosa que é conquistada com o método fenomenológico. Começa-se a pensar, então, como a psicologia pode trazer para o projeto fenomenológico uma de suas bases fundamentais: a maneira como o sujeito husserliano está consistentemente em relação ao mundo, a partir do aspecto vivencial, ou seja, não se trata de um sujeito isolado, mas sim daquele que, por meio da intencionalidade, está em contato direto com o mundo.

A partir disso, a fenomenologia pode se inserir, auxiliada pelo que pode se chamar de psicologia fenomenológica, como outra forma de se pensar, diferente de todas as teses positivistas e objetivistas. Mas a fenomenologia husserliana, como está sendo elaborada a partir daqui, pode ser definida em dois momentos (Castro \& Gomes, 2011). O primeiro modo se deu a partir do que se chama de fenomenologia eidética, que tinha o objetivo de, por meio das reduções fenomenológicas, descrever rigorosamente os fenômenos. Segundo Sacrini (2009), esta fenomenologia descrevia as experiências vividas, mas não no sentido simplesmente empírico, mas as vivências puras, a essência mesmo do fenômeno que se apresenta. Mas estas experiências vividas e puras só conseguem ser pensadas a partir daquilo que Husserl caracteriza como redução. Neste primeiro modo de se constituir da fenomenologia, segundo Depraz (2011), podemos caracterizar duas formas de redução. A primeira consiste na conversão reflexiva, aquela que faz o sujeito desviar parcialmente a atenção dada ao mundo e encontrar a si mesmo. A segunda é a própria redução eidética, ou seja, não é apenas uma redução que volta o sujeito a si mesmo, fundada em um caráter psicológico, mas que aponta para a essência das coisas mesmas, na experiência vivida do próprio fenômeno. É uma redução que consiste em não simplesmente se considerar os "fatos puros", como era na concepção positivista, mas sim os fenômenos por eles mesmos, em sua essência, que são dados a partir do que Husserl chamou de "variação eidética", ou seja, aquilo que é invariante do fenômeno, sua essência, que não muda com a alteração de seu perfil, forma. Para Capalbo (2007), "as essências emergem da variação que eu submeto às coisas pela imaginação, a fim de verificar o que poderia modificar a coisa sem que a coisa cesse de ser o que ela é nela mesma” (p. 27).

Já o segundo momento é caracterizado como sendo o da fenomenologia transcendental, que tinha o objetivo de servir de fundamentação rigorosa de todo e qualquer conhecimento, e a única possibilidade, associada à psicologia fenomenológica, de superar as insuficiências advindas da própria ciência. Segundo Feijoo (2011b), "Husserl defende que o lugar onde a filosofia deve permanecer é o do projeto moderno, ou seja, na vontade de se constituir como ciência rigorosa” (p. 26). Portanto, o que passa a estar em jogo não é simplesmente descrever os fenômenos, mas sim buscar aquilo que sempre esteve presente no pensamento de Husserl: uma fundamentação rigorosa da própria ciência em geral. Esta mesma possibilidade de fundamentação rigorosa das ciências só é possível através da apropriação do método intencional, como apontamos anteriormente. Porém, a intencionalidade da consciência, como Husserl vai conceber a partir da formulação de seu "ego transcendental”, está relacionada ao conceito de correlação universal. Segundo Goto (2007), este conceito aponta para o fato de que a consciência necessita de seus objetos para se constituir, e os objetos só podem ser concebidos a partir da relação que a consciência, como consciência intencional, pode estabelecer para com eles. Não existe consciência sem objeto, e nem objeto sem consciência. Esse é o próprio movimento intencional, e que Husserl tentou acabar com a possibilidade de perpetuar a dicotomia sujeito e objeto. E é através disso que acaba se realizando a redução do próprio sujeito, anteriormente empírico e cognoscente, para uma relação direta entre a consciência intencional e seu objeto, que coexistem. A fenomenologia neste momento também se afasta de uma compreensão psicológica no sentido de a vivência é desvelada por uma consciência que só se constitui com a possibilidade de um objeto, e não como uma estrutura mental/fisiológica que existe por ela mesma, defendida por teorias psicológicas.

\section{A hermenêutica de Dilthey}

Assim como a fenomenologia husserliana acompanha o movimento desta crise que descrevemos acima, a hermenêutica diltheyana também se insere na mesma, porém com certas diferenciações que serão as bases fundamentais para o seu entendimento. Podemos dizer que a influência direta no movimento hermenêutico é a de Schleiermacher, que traz a questão de se pensar a subjetividade e a objetividade no texto. Esta é uma herança de suma importância, e vai permanecer no pensamento de Dilthey por toda a sua obra, principalmente em suas análises a respeito das ciências naturais e humanas, como veremos em seguida. Cabe agora afirmar, segundo Franco (2012), que objetivamente a interpretação busca as questões histórico-gramaticais e, subjetivamente, a compreensão psicológica do autor do texto. Desta forma, Dilthey vai além de uma leitura sistemática do movimento religioso, e passa a entender a hermenêutica de forma mais abrangente.

É a partir desta ideia da contraposição da objetividade com a subjetividade, que Dilthey começa a inserir a sua crítica acerca da absolutização que as ciências naturais exercem como as únicas detentoras da verdade. Isto é o 
começo da inserção de Dilthey na crise dos universais e pode, assim como Husserl, ser considerado um antipositivista. Pode-se perceber estes esforços em Dilthey (1894/2011), onde ele, seguindo já o caráter da objetividade/subjetividade, busca uma fundamentação rigorosa para as ciências humanas, ou como ele também as chama, as ciências do espírito. Ele tenta, consistentemente, elevar as ciências do espírito ao mesmo patamar que as ciências naturais. E, para isso, tece algumas críticas a respeito desta. Aferindo, ainda, que as ciências naturais conseguem realizar tal movimento de absolutização a partir do método explicativo, que necessariamente recorta os fenômenos de seu campo de mostração originário, ou seja, recorta os fenômenos de seu horizonte hermenêutico.

Kahlmeyer-Mertens \& Kisse (2012) apontam um acontecimento análogo a este da explicação e autonomização das ciências naturais, com a maneira que os movimentos metafísicos se inserem na história e se colocam como os detentores da verdade. Este movimento é bem marcado em toda a história da filosofia, e acaba acompanhando a forma como a explicação pode ser concebida. Tanto as ciências naturais quanto a metafísica buscam necessariamente explicações acerca das coisas em geral. E este movimento explicativo ocasiona aquilo que pode ser chamado de "desvificação" do próprio mundo. Os aspectos universais aqui são estabelecidos por meio da desvificação de mundo, através de uma visão de mundo particular.

Em contraposição ao movimento explicativo, temos aquilo que Dilthey (1894/2011) chama de compreensão. A compreensão está atrelada à possibilidade de se elevar as ciências do espírito a um grau de cientificidade como o das ciências naturais. A compreensão busca, como nos diz Franco (2012), enxergar o universal presente no particular, e o todo nas partes.

Porém, o movimento compreensivo pode se constituir de duas formas no pensamento diltheyano. Segundo Kisse (2012), há duas formas de se pensar a compreensão. A primeira é aquela "elementar”, ou psicológica, que estaria relacionada com um caráter vivencial para com o outro, que possui o mesmo espírito objetivo que o intérprete. A segunda forma de compreensão é considerada "mais elevada" que a primeira, pois o espaço em que se dá a compreensão não é aquele compartilhado objetivamente pelo espírito do intérprete, mas sim advindo de outras "concepções de mundo".

As formas de compreensão estão necessariamente relacionadas com o conceito de vivência, no projeto hermenêutico de Dilthey. Segundo Casanova (2012) essas "vivências, contudo, não se reduzem ao âmbito de realização do singular, porque se encontram desde o princípio imersas no campo de objetivação daquilo que Dilthey denomina “a vida do espírito” (p. 35). Portanto, o aspecto vivencial aponta para um entendimento acerca do próprio aspecto da objetividade. O particular está automaticamente ligado às concepções universais de seu tempo. Aqui, esta possibilidade do particular se unir às concepções objetivas de seu tempo, é dado por meio da compreensão. O sujeito não é afastado de seu objeto nos moldes positivistas, mas através da compreensão intuitiva, segundo Dilthey (1894/2011), se consegue sair do particular para o universal. Tudo isto nos leva à compreensão do termo vida, colocado novamente por Dilthey. Vida aqui é entendida como a realidade psicofísica, ou seja, é a supressão da dicotomia sujeito e objeto, para uma compreensão que pensa a história diferentemente do projeto hegeliano, de uma história idealizada. Aqui história é levada à concretude que abarca tanto os aspectos físicos quanto psíquicos de um tempo.

Desta maneira, conseguimos entender como Dilthey está em um constante diálogo com a psicologia. Tanto é que em momentos tardios de sua obra procura fundamentar, como em Dilthey (1894/2011), uma psicologia descritiva e analítica, que utilize da compreensão hermenêutica como método fundamental para se pensar os fenômenos psíquicos. Esta psicologia é contraposta às psicologias explicativas de seu tempo, de cunho positivista-natural, que tem como seu método a explicação. A explicação, como foi apontada, apenas recorta o fenômeno da própria vida de seu tempo, desvificando toda a história na absolutização de visões de mundo particulares, traço fundamental da crise dos universais, que tanto Dilthey quanto Husserl buscaram superar.

\section{A aproximação da fenomenologia hermenêutica de Heidegger}

Husserl e Dilthey teciam críticas recíprocas, segundo Lessa (2011), e a partir da maneira com que cada um leva a cabo seu próprio projeto fica evidente certas "desconsiderações” que cada um acabou fazendo. Porém, é a partir destas desconsiderações que iremos apresentar o trabalho de Heidegger como sendo o da fenomenologia hermenêutica. Heidegger articula o pensamento destes dois filósofos e formula sua obra Ser e Tempo, em que pensa a própria possibilidade de uma ontologia ser possível, e de que maneira esta ontologia pensada por ele, a ontologia fundamental, pode perguntar acerca do sentido do ser. O mesmo autor afirma que, de acordo com Heidegger, Husserl descobriu algo revolucionário: a intencionalidade. Porém, esta descoberta ainda estava imersa na mesma linguagem que a filosofia moderna, ou seja, ainda tratava dos mesmos pressupostos subjetivos presente desde Descartes. Desta forma, Heidegger vai se diferenciar ao não se perguntar pelo “o que é o homem?”, tomando-o como algo certo e indubitável, mas sim "quem é o homem?".

Machado (2010) afirma que Heidegger, após ter criticado Husserl de ser ainda cartesiano e intelectualista, abandonou conceitos tanto de intencionalidade quanto de consciência, que eram os pilares fundamentais da fenomenologia de Husserl. Porém, é preciso lembrar que 
este "abandono" foi muito mais uma mudança em relação aos conceitos, mas que ainda terá em seu cerne muitos pontos similares aos mesmos, o que será melhor tratado a partir de agora. Em Heidegger, segundo Ferreira (2009), não há mais a consciência intencional. Toda e qualquer possibilidade de tratamento a partir da dicotomia sujeito e objeto é excluída aqui. Heidegger criticava ainda a posição em que Husserl se colocou, pois apenas acompanha o movimento que é caracterizado pela separação entre de sujeito e objeto. Mas Heidegger não se pergunta pelo sujeito, pela essência mesma das coisas, no sentido de uma essência ideal. Mas então de que forma Heidegger irá se aproximar de Husserl?

Tratando ainda da crítica feita a Husserl de que este se insere diretamente em considerações da mesma dicotomia que tanto criticou, Heidegger, de acordo com Depraz (2011) “propõe mudar o nome que se dá habitualmente à instância intersubjetiva: o ego husserliano se torna um Dasein, um “existente”, literalmente um "ser-aí” (p. 90). Portanto, Heidegger faz mais do que criticar, e traz a sua proposta de se pensar a partir do ser-aí, como fica evidente em seu fundamental parágrafo 9 de Ser e Tempo (1927/2012), onde expõe as principais considerações acerca deste existente.

Para Machado (2010), o Dasein se justifica por si mesmo, e foi o passo fundamental para realizar a articulação de suas formulações com o pensamento de seu mestre, Husserl. Heidegger toma este ente, o Dasein, e retira qualquer necessidade de abstração para se chegar a um conhecimento essencial e transcendental acerca dos fenômenos. Aqui, o Dasein passa ser a própria dinâmica do conhecimento, a sua própria existência já exerce ontologicamente uma compreensão prévia acerca do mundo.

Como afirmamos anteriormente, a noção de intencionalidade é modificada em Heidegger. Segundo Zuben (2011), o ser-aí é a própria "luz e revelação", e não de um modo teórico no tratamento dos fenômenos e dos entes no mundo, mas sim na própria possibilidade de vivência existencial, ou seja, o ser-aí que está lançado em seu mundo fático e sedimentado, não é mais um ego separado do mundo, mas sim um ente que em qualquer possibilidade de compreensão, já compreende o ser. O ser-aí é em si mesmo intencionalidade. Heidegger continua o trabalho de Husserl a partir de uma nova compreensão do existir humano.

De acordo ainda com Zuben (2011), Husserl consegue alcançar a "volta às coisas mesmas" por meio da redução, em que existe um distanciamento do mundo fático. Porém, Heidegger não toma a mesma posição, e pensa o ser-aí como aquele ente que já, de início e na maioria das vezes, se encontra na compreensão mesma dos entes intramundanos, que surgem em seu mundo. Segundo Casanova (2012), a maneira com que Heidegger vai pensar a redução será a partir do movimento do que podemos chamar de "destruição da história da ontologia". Heidegger pensa diferente o método da redução, não como uma suspensão, mas como a possibilidade de reconquista do horizonte originário de mostração dos entes em geral, ou seja, a possibilidade de desvelar as camadas semânticas da tradição, para que o questionamento acerca do ser seja possível, a partir do ser-aí.

Já em relação a Dilthey, Heidegger também se posiciona de forma crítica e busca uma forma de se pensar a hermenêutica diltheyana a partir da junção com as próprias possibilidades da fenomenologia. Para Heidegger, uma não poderia ser pensada sem a outra. Segundo Lessa (2011), Heidegger pensa que Dilthey se insere em um chamado "relativismo histórico", devido ao fato de que não consegue pensar para além das determinações históricas de um tempo. Na realidade, a crítica se volta para a questão de que o sujeito diltheyano é determinado por uma desconsideração do conteúdo ideal dos fenômenos e da significatividade que vai além da própria história.

Ainda, em relação a estas questões referentes à Dilthey, Lessa (2011) afirma que "o que ele não percebe é que, por mais que se tenha um horizonte hermenêutico, podemos pensar a pluralidade ontológica do mundo a partir dos comportamentos intencionais do ser-aî” (p. 71). Portanto, não se trata aqui, no projeto da ontologia fundamental heideggeriana, de pensar as modulações existenciais do ser-aí a partir de um horizonte hermenêutico estagnado, que compreende a ascensão de uma visão de mundo por meio de um jogo entre visões de mundo particulares e relativas. O que está em jogo aqui é a própria possibilidade do ser-aí, em sua compreensão mesma do ser, fundar o próprio horizonte hermenêutico através de sua dinâmica existencial.

A maneira com que Heidegger elabora os conceitos de vivência e compreensão são apontados, por Casanova (2012), como sendo diferentes das concepções de Dilthey. A questão da vivência é entendida a partir de Heidegger em contraposição à postura teorética e intuitiva. A própria possibilidade de compreensão está embasada na vivência. Isto se dá no sentido de que o ser-aí, como um existente, já está de início e na maioria das vezes, na compreensão dos fenômenos do mundo. Esta apreensão não é a mesma de uma postura teórica, mas sim vivencial. O mesmo autor ainda traz um exemplo do próprio Heidegger, da maneira como esta abertura vivencial-compreensiva se dá no mundo. Uma cátedra pode ser explicada teoricamente a partir de uma descrição de suas partes constituintes, do material de que foi feita, e também de seu tamanho. Mas esta posição teórica é tardia, pois antes mesmo de nos colocarmos na posição teórica e objetiva, assim como acontece com as ciências naturais, já compreendemos a cátedra como ela mesma se apresenta no seu uso. A cátedra não se apresenta como uma estrutura de madeira que possui determinado tamanho e medida. Mas, ela é entendida como aquele instrumento que está inserido em um contexto de sentido que é o da cátedra, ou seja, a sua forma de uso, a sua serventia. Esta questão de sentido instrumental é fundamental na concepção 
heideggeriana, pois também escapa da ingenuidade "psicofísica” com que Dilthey considera o fenômeno da vida, de sua hermenêutica. Assim, afirma Ferreira (2009), que o "compreender" passa a ser o "poder lidar com algo", e, com isso, um "situar-se no mundo", para o ser-aí.

Desta maneira, realizamos a aproximação proposta no início do presente artigo. Cabe agora pensar de que maneira esta mudança de pensamento, em relação a Husserl e Dilthey, por parte de Heidegger a partir de sua fenomenologia hermenêutica de Ser e Tempo, pode contribuir para uma clínica que não desconsidera o caráter fático e existencial do paciente. Uma clínica que também exclui de seu método o entendimento do paciente a partir das considerações positivistas e até mesmo ingênuas, que tomam a dicotomia sujeito e objeto como o pilar fundamental de suas possibilidades.

\section{A clínica fenomenológica hemenêutica com bases heideggerianas: a daseinsanalyse}

Segundo Roriz (2010), a palavra clínica “vem do grego Kline: leito, cama. Já o termo Klinikós refere-se ao modo de atender os doentes que estão acamados, visto em função daquele que se inclina, debruça-se bem próximo ao paciente que está no leito e o acolhe” (p. 50). Esta passagem nos mostra a maneira que iremos considerar a clínica fenomenológica hermenêutica, em contraposição com as demais formas de se pensar a clínica em psicologia. Aqui, o que passa a ser fundamental é este cuidado, este acolhimento que levará o paciente às suas próprias possibilidades, e não intervenções por parte do terapeuta para que o paciente "melhore", ou seja, "curado" de seus "problemas".

A aproximação dos fundamentos da Daseinsanalyse à prática clínica se originou com a aproximação da psiquiatria, a chamada psiquiatria fenomenológica do fim do século XIX e início do XX, com as contribuições de Jaspers, Minkowski, Von Gebsattel entre outros. Mas foi com Ludwig Binswanger (1881-1966) e, principalmente, com Medard Boss (1903-1990) que há um significativo avanço em relação às psicoterapias.

A prática da Daseinsanalyse, proposta por Boss, se apresenta ancorada nas obras Ser e Tempo e contribuições posteriores, principalmente os Seminários de Zollikon (entre 1959 a 1969), entre outras, propostas por Heidegger após 1930. Buscava-se, através dos fundamentos da Daseinsanalyse apresentar, seja pela leitura de alguns casos clínicos ou pela proposta de aproximação da filosofia heideggeriana para o contexto psicológico, uma prática psicológica. Desta maneira, buscou-se refletir sobre as intervenções terapêuticas, alicerçadas no método fenomenológico e de investigação hermenêutica. Assim, podemos nos aproximar do que caracteriza a prática clínica fenomenológica hermenêutica. O que se busca é um processo hermenêutico que visa a compreensão de si-mes- mo (selbst), do ser-aí, acompanhando o modo como essa compreensão da sua condição como "ser-em-o-mundo" (In-der-Welt-sein) se desdobra no seu existir. "Ser-em-omundo", é, segundo Heidegger (1927/2012), o existencial que apresenta a forma como o ser-aí está lançado de início e na maioria das vezes no mundo fático que é seu, e também aponta a forma como Heidegger superou a antiga dicotomia sujeito e objeto.

O compromisso clínico não é com a mudança, mas sim com uma aproximação existencial do paciente aos seus modos de ser. Desta forma, de acordo com Ferreira (2010), há a busca da compreensão do modo como o paciente experimenta a sua vida, e não a patologia. O caráter fundamental de ser-no-mundo revela que o paciente, como ser-aí, está sempre lançado em um horizonte de possibilidades, e não pode se fechar em diagnósticos prontos, como se concebe a partir das determinações positivistas. Aqui se busca um espaço que abre a possibilidade de sentido para o paciente.

A concepção heideggeriana de "ser-aí" é aquela em que o ente que existe está relacionado ao aí no mundo. Este ponto para a relação terapêutica se mostra como essencial em um projeto de atendimento fenomenológico hermenêutico, já que o espaço terapêutico se mostra para o paciente como sendo seu próprio mundo. Este é constituído pela totalidade de significados, de referências que pertencem ao próprio ser-aí. Porém esta questão é esquecida, segundo Sá e Santos (2011), devido ao fato do homem moderno se ver solicitado por diversos estímulos que o obrigam a se atualizar e buscar sempre a questão da produtividade. Devido a isso, o espaço terapêutico é muitas vezes visto como aquele que deve produzir uma "melhora", uma mudança no paciente, aos moldes positivistas. Porém, este espaço é como um dos modos de ser, do ser-aí, portanto deve permitir que a existência se desvele por ela mesma.

Seguindo ainda a caracterização acerca do ser-aí, se pode afirmar: o ser-aí é o aí, ele é o seu mundo. E o espaço terapêutico, que também pode ser entendido como um espaço do ser-aí, de seu mundo, não é um espaço simplesmente dado e posicionado, de acordo com os parâmetros das ciências naturais. Segundo Sodelli \& Sodelli-Teodoro (2011), o espaço terapêutico é aquele que estabelece a possibilidade do paciente se apropriar do seu si-mesmo, ou seja, de suas próprias possibilidades como ser-aí. A narrativa do paciente desvela este ser-no-mundo em suas possibilidades, já que este, sendo um ser-aí, se apresenta como a sua abertura existencial. Já não cabe mais simplesmente pensarmos o homem e suas vivências segundo os parâmetros de interno/externo e a partir de conceitos elaborados pelas teorias de psicologia que partem das concepções de processos subjetivos, internos ou observações mecanicistas do comportamento, por exemplo.

\footnotetext{
In-der-Welt-sein, apresenta-se na tradução de Ser e Tempo de Márcia Sá Cavalcante Schuback (2002) "como ser-no-mundo".
} 
Existe a impressão de que sem estes mesmos pressupostos cristalizados não é possível compreender o que é um ser humano, ou o que é uma pessoa, como e de onde se originam os problemas humanos. Também não teremos como saber o que faz parte da pessoa e o que é vindo do mundo. Em resumo, existe a impressão de que, caso não exista uma teoria de psicologia como retaguarda, não é possível compreender o paciente. De acordo com Lessa (2011), no "interior de uma psicologia com bases heideggerianas, por outro lado, os problemas são sempre problemas do ser-no-mundo” (p. 188). Aqui não é pensando mais em termos psíquicos interiorizados, e sim a própria dinâmica da existência, o ser-aí. Passado esse primeiro momento, descobrimos que se suspendermos aqueles conceitos e pressupostos da tradição, temos à disposição todo um referencial que permite a abertura para uma compreensão do fenômeno de existência humana no que ela tem de mais profundo. A partir daí, aquelas noções de esferas internas, de mundo externo e sua realidade objetiva, não nos fazem mais falta. Cessa aquela sensação de estranheza e desabrigo que havíamos sentido quando certos conceitos que pareciam indiscutíveis foram abalados e começamos a ter confiança no novo que encontramos.

Vamos nos aproximando aos poucos, desta forma, da constituição do ser-aí como ser-no-mundo, e da possibilidade de uma apropriação clínica. Segundo Heidegger (1927/2002), existir é “poder-ser”. Como a mais originária determinação ontológica do ser-aí, esta se mostra fortemente no viés clinico já que sempre há novas possibilidades de aberturas existenciais, e o espaço clinico pode facilitar tais modos de ser. Estas aberturas, segundo Sodelli \& Sodelli-Teodoro (2011), são as próprias aberturas para a experiência dos fenômenos que se apresentam. Não se trata como deixamos claro anteriormente de um contato ideal e teórico com as coisas, mas com as coisas "em si mesmas", aquelas dadas na experiência-compreensiva que é a própria existência, o próprio ser-aí.

A abertura compreensiva (Verstehen) e a abertura afetivamente disposta (Befindlichkeit) (Heidegger, 1927/2012), respectivamente "entender" e "encontrar-se", caracterizam o ser-no-mundo e já são sempre articuladas no discurso (Sprache). O discurso é a articulação da compreensibilidade e é cooriginário com o compreender e com a disposição afetiva, segundo Heidegger (1927/2002). Vivendo faticamente num mundo, o ser-aí já é sempre decaído no mundo. Essa decadência constitui o modo cotidiano de ser-no-mundo absorvido pelo mundano e pela coexistência dos demais. O ser-aí decaído se extravia de seu poder-ser si-mesmo, próprio, e se perde na impropriedade do impessoal, naquilo que é o de todos. O espaço da terapia pode ser um pontuador que se apresenta a cada um em seu mundo e não um espaço de busca de singularização. Essa busca de cada um em seu mundo, segundo Roriz (2010), pode ser entendida na maneira como a clínica que estamos aqui propondo, busca uma apropriação temática da fala impessoal do paciente. E ao mesmo tempo em que o paciente tem contato com as determinações impessoais de seu mundo, ele passa, na psicoterapia, a perceber novas possibilidades que lhe são próprias.

Cabe agora pensar a respeito de um último ponto, que se mostra como aquele mais pertinente para a clínica que estamos buscando no presente artigo. Este ponto é do fundamento ontológico da estrutura do cuidado, portanto, fundamento existencial do ser-aí. Segundo Heidegger (1927/2002), o cuidado é entendido a partir de dois modos possíveis: o da ocupação (Besorgen), e o da preocupação (Fürsorge). A ocupação vai tratar da forma como o ser-aí está em constante relação com os entes intramundanos, de caráter instrumental e de uso, como ferramentas: martelo, prego, cadeira. Porém, a preocupação, como forma de cuidado, se apresenta como aquela que coloca o ser-aí em meio à relação com os demais seres-aí em seu mundo e, no próprio ambiente terapêutico, a estrutura da preocupação se faz presente como aquela que desvela a relação paciente-terapeuta.

No processo de terapia há a busca neste espaço que apresenta novas possibilidades de ser do paciente. Segundo Ferreira (2010), o cuidado na terapia pode ser entendido como o acompanhar o paciente na sua própria libertação, por parte do terapeuta. Libertação aqui não é entendida como supressão das determinações do horizonte em que o paciente está inserido, mas sim como a dinâmica existencial em que, a partir do cuidado, na terapia, o paciente passa a se apropriar de novas possibilidades de lidar com o seu sofrimento.

Com tudo isso, conseguimos nos aproximar da maneira como Heidegger, a partir da articulação entre o pensamento de Husserl e Dilthey, de seus conceitos mais fundamentais e também de suas próprias contribuições filosóficas, fornece a possibilidade para que outros autores possam embasar uma prática clinica em psicologia. Nesta clínica se busca a coerência em uma compreensão aprofundada em termos de ser-no-mundo frente às suas possibilidades, pela existência do nosso paciente que se apresenta em sua narrativa. No seu narrar a possibilidade é a de um "estar junto" no processo de terapia e não uma entrega de concepções preconcebida nos métodos tradicionais. E é nisto que se funda o cuidado, pois, segundo Lessa (2011), é no estar junto com os outros seres-aí que cada um cuida de si e, portanto, o mesmo acontece na relação terapêutica, na forma de uma libertação do paciente para si-mesmo.

Cabe ainda fazer as últimas considerações a respeito das possibilidades de se pensar uma clínica sem psiquismo. A partir do presente artigo afirmamos que é possível pensar o paciente, aquele que procura auxílio na clínica, diferentemente dos pressupostos da tradição. Pensar fenomenologicamente e hermeneuticamente significa considerar aquilo que se apresenta na terapia, como fenômenos em si mesmos, e que possuem um lugar na própria história. Quanto a esta tarefa de se pensar uma clínica fenomenológica hermenêutica, Feijoo (2011b) afirma que 
tanto Biswanger e Boss deixaram "vários aspectos que precisaram ser repensados, uma vez que ainda guarda elementos de influências da Psicologia e da Psiquiatria inseridos no momento em que eles desenvolviam a sua daseinsanálise" (p. 202-203). Portanto, o caminho para se pensar uma Daseinsanalyse de fato, está aberto. O presente artigo buscou apresentar a possibilidade de se pensar uma clínica que tratasse essencialmente da existência mesma do paciente. Deste modo, as discussões não se encerram aqui, pelo contrário, se abrem diversos caminhos para que a clínica fenomenológica hermenêutica possa ser concretizada fielmente à luz do projeto filosófico de Heidegger.

\section{Referências}

Boris, G. D. J. B. (2011). A (pouca conhecida) conhecida contribuição de Brentano para as psico terapias humanistas. Revista da Abordagem Gestáltica, 17(2), 193-197.

Capalbo, C. (2007). A subjetividade e a experiência do outro: Maurice Merleau Ponty e Edmund Husserl. Revista da Abordagem Gestáltica, 13(1), 25-50.

Casanova, M. A. (2012). Compreender Heidegger (3. ed.). Petrópolis, RJ: Vozes.

Castro, T. G., \& Gomes, W. B. (2011). Movimento fenomenológico: controvérsias perspectivas na pesquisa psicológica. Psicologia: teoria e pesquisa, 27(2), 233-240.

Depraz, N. (2011). Compreender Husserl. (F. dos Santos, Trad.). (3. ed.). Petrópolis, RJ: Vozes.

Dilthey, W. (2011). Ideias sobre uma psicologia descritiva e analítica. (M. A. Casanova, Trad.). Rio de Janeiro, RJ: Via Verita. (Original publicado em 1894).

Feijoo, A. M. L. C. (2011a). A crise da subjetividade e o despontar das psicologias fenomenológicas. Psicologia em estudo, 16(3), 409-417.

Feijoo, A. M. L. C. (2011b). A existência para além do sujeito: a crise da subjetividade moderna e suas repercussões para a possibilidade de uma clínica psicológica com fundamentos fenomenológico-existenciais. Rio de Janeiro, RJ: Via Verita.

Ferreira, L. S. M. (2009). Entre a fenomenologia e a hermenêutica: uma perspectiva em psicoterapia. Revista da Abordagem Gestáltica, 15(2), 143-148.

Ferreira, L. C. R. (2010). Reflexões acerca das contribuições de Heidegger para uma clínica fenomenológica-existencial. Dissertação de mestrado, Universidade Federal Fluminense, Niterói.

Franco, S. G. (2012). Dilthey: compreensão e explicação e possíveis implicações para o método clínico. Revista latino-americana de psicopatologia fundamental, 15(1), 14-26.

Goto, T. A. (2007). A (re) constituição da psicologia fenomenológica em Edmund Husserl. Tese de doutorado, Universidade Pontifícia Católica, Campinas.
Heidegger, M. (2012). Ser e Tempo. (F. Castilho, Trad.). São Paulo-Petrópolis: Editora Unicamp-Vozes. (Original publicado em 1927).

Heidegger, M. (2002). Ser e Tempo. (12. ed.) (M. S. C. Schuback, Trad.). Petrópolis: Vozes: Universidade São Francisco. (Original publicado em 1927).

Holanda, A. F. (2009). Fenomenologia e psicologia: diálogos e interlocuções. Revista da Abordagem Gestáltica, 15(2), 87-92.

Kahlmeyer-Martens, R. S. \& Kisse, E. H. S. (2012). Sobre o estatuto do psiquismo no projeto hermenêutico de Wilhelm Dilthey. Ekstasis: revistas de hermenêutica e fenomenologia, 1(1).

Kisse, E. H. S. (2012). O conceito de hermenêutica e sua aplicação no pensamento de W. Dilthey. Revista Litteris, 10(1).

Lacerda, G. B. (2009). Augusto Comte e o "positivismo" redescobertos. Revista de Sociologia e Política, 17(34), 319-343.

Lessa, J. M. (2011). Princípios fundamentais de uma prática psicoterápica com bases fenomenológico-existenciais. Tese de doutorado, Universidade Federal Fluminense, Niterói.

Machado, B. M. (2010). Heidegger e a superação da crise dos fundamentos: antecedentes para a proposição de uma ontologia fundamental. Estudos e pesquisa em psicologia, 10(3), 765-780.

Roriz, J. C. (2010). Psicoterapia fenomenológica-existencial: acolhimento e tematização da angústia. Dissertação de Mestrado, Universidade Federal Fluminense, Niterói.

Sá, R. N., \& Santos, D. G. (2011, setembro). A existência como "cuidado": elaborações fenomenológicas sobre clínica psicoterapêutica. Comunicação apresentada no IV Congresso de Fenomenologia da região Centro-Oeste.

Sacrini, M. (2009). O projeto fenomenológico de fundação das ciências. Scientiæ zudia, 7(4), 577-593.

Sodelli, M., \& Sodelli-Teodoro, A. (2011). Visitando os "Seminários de Zollikon": novos fundamentos para a psicoterapia fenomenológica. Psic. Rev. São Paulo, 20(2), 245- 272.

Zuben, N. (2011). A fenomenologia como retorno à ontologia em Martin Heidegger. Trans/form/ação, 34(2), 85-102.

Jean Luca Lunardi Laureano da Silva - Graduando do curso de Psicologia da Universidade de Mogi das Cruzes (UMC).

E-mail: jeanluca10@gmail.com

Marina Valente Guimarães Cecchini - Professora de Fenomenologia Existencial da Universidade de Mogi das Cruzes (UMC) e Doutoranda da Faculdade de Medicina da Universidade de São Paulo (USP). E-mail: cecchini.nina@gmail.com

Recebido em 11.08.2013 Primeira Decisão Editorial em 07.12.2013 Aceito em 31.01.2015 